\title{
Dynamic Changes in the Rice Blast Population in the United States Over Six Decades
}

\author{
Xueyan Wang, ${ }^{1,2}$ Yulin Jia, ${ }^{2,+}$ Yeshi Wamishe, ${ }^{1}$ Melissa H. Jia, ${ }^{2}$ and Barbara Valent ${ }^{3}$ \\ ${ }^{1}$ Rice Research and Extension Center, University of Arkansas, Stuttgart, AR 72160, U.S.A.; ${ }^{2}$ Dale Bumper National Rice \\ Research Center, USDA, ARS, Stuttgart, AR 72160, U.S.A.; and ${ }^{3}$ Kansas State University, Manhattan, KS 66506, U.S.A.
}

Accepted 30 June 2017.

\begin{abstract}
Rice blast disease caused by Magnaporthe oryzae is one of the most destructive diseases of rice. Field isolates of $M$. oryzae rapidly adapt to their hosts and climate. Tracking the genetic and pathogenic variability of field isolates is essential to understand how $M$. oryzae interacts with hosts and environments. In this study, a total of 1,022 United States field isolates collected from 1959 to 2015 were analyzed for pathogenicity toward eight international rice differentials. A subset of 457 isolates was genotyped with 10 polymorphic simple sequence repeat (SSR) markers. The average polymorphism information content value of markers was 0.55 , suggesting that the SSR markers were highly informative to capture the population variances. Six genetic clusters were identified by both STRUCTURE and discriminant analysis of principal components methods. Overall, Nei's diversity of M. oryzae in the United States was 0.53 , which is higher than previously reported in a world rice blast collection ( 0.19$)$. The observed subdivision was associated with collection time periods but not with geographic origin of the isolates. Races such as IC-17, IE-1, and IB-49 have been identified across almost all collection periods and all clusters; races such as IA-1, IB-17, and IH-1 have a much higher frequency in certain periods and clusters. Both genomic and pathogenicity changes of United States blast isolates were associated with collection year, suggesting that hosts are a driving force for the genomic variability of rice blast fungus.
\end{abstract}

Plants, unlike animals, don't possess the ability to escape stresses from their surroundings. Evolutionarily, plants have evolved a multifaceted defense system to cope with both biotic and abiotic stresses. Consequently, pathogenic microorganisms have evolved sophisticated adaptive strategies to survive in nature. In the classic plant disease triangle, changes in environmental conditions over time influence the outcome of genetic architectures of both plants and pathogens, and these two organisms are undergoing selective pressure from each other. Population genetic analysis of a plant pathogen can provide information on the major evolutionary forces imposed on the pathogen's population. Rice (Oryza sativa) is one of the most important food crops and has been under cultivation for

${ }^{\dagger}$ Corresponding author: Y. Jia; E-mail: yulin.jia@ars.usda.gov

*The $\boldsymbol{e}$-Xtra logo stands for "electronic extra" and indicates that eight supplementary figures and twelve supplementary tables are published online.

This article is in the public domain and not copyrightable. It may be freely reprinted with customary crediting of the source. The American Phytopathological Society, 2017. thousands of years in diverse global locations. The Ascomycete fungus Magnapothe oryzae (synonym of Pyricularia oryzae) is the causal agent of rice blast disease. This disease has been one of the most devastating diseases, resulting in significant crop loss at times wherever rice is widely grown. In the United States, blast disease has been detected in all of the major riceproduction areas of the southern United States and also in California (Marchetti et al. 1976). Because United States rice is a single crop per year production system grown on floodirrigated land planted with early maturing rice cultivars that possess some resistance $(R)$ genes and rotated with nonhost crops, blast disease has not been a widespread problem, particularly in the southern United States (Marchetti 1983). With constant changes in rice-production practices, such as reduction of water resources, increased deployment of highyielding rice cultivars with a narrow genetic base, and high fertility inputs, rice blast disease is an ongoing threat. Reduced crop yield due to rice blast was most notably in 1970, 1987, and 2004, on United States cultivars such as Newbonnet and Banks (Lee 1994; Lee et al. 2005). A recent study predicted that $\$ 61 \mathrm{M}$ is expended per year in the mid-south of the United States as a control measure for rice blast disease (Nalley et al. 2016).

Monitoring pathogenicity and genetic shifts of the blast fungus in commercial fields is imperative to managing rice blast disease. Differences in pathogenicity of $M$. oryzae resulted in the identification of physiological races by use of differential rice varieties in Japan in 1961. Also around this time, a set of eight international rice differentials (IRD), consisting of indica Raminad Str. 3, tropical japonica Zenith, indica/AUS NP125, indica Usen, AUS Dular, temperate japonica Kanto 51, temperate japonica Sha-tiao-tsao, and temperate japonica Caloro varieties, was established to assign 256 pathogenic races (Atkins et al. 1967). The term "race" determined with IRD was used as an indicator of pathogenicity. When a race changes, pathogenicity of that isolate of $M$. oryzae also changes. Ever since its establishment, this differential system has been effectively used to infer aggressiveness of the rice blast fungus and host genetic resistance worldwide.

Genetic shifts of $M$. oryzae have been documented with the use of M. grisea repetitive (MGR586) DNA fingerprint using Southern blotting and repetitive polymerase chain reaction (Rep-PCR) (Valent and Chumley 1991). Namely, 56 lineages were identified in India (Kumar et al. 1999), 12 in China (Chen et al. 2006) and Vietnam (Thuan et al. 2006), 10 in the Philippines (Chen et al. 1995), six in Colombia (Levy et al. 1993), six in Japan (Don et al. 1999), and two in Korea (Park et al. 2008). The blast isolates in the United States were classified into eight lineages (A through $\mathrm{H}$ ) and only four appear to be commonly found in the 1990s (Correll et al. 2000; Levy et al. 
1991; Xia et al. 1993, 2000). It was reported that host selection may affect change in host specificity (Zeigler 1998). Chen et al. (1995) sampled 1,516 monoconidial M. oryzae isolates from 38 rice accessions in two locations and identified the largest proportion of differentiation due to host selection. Xia et al. (2000) recovered a total of 470 isolates from eight rice cultivars from 18 commercial fields in rice-growing counties in Arkansas. They found a strong bias for lineage B on cultivar M204 and lineage A on cultivar Mars, suggesting that some rice cultivars were effective in excluding certain lineages based on the presence of resistance $(R)$ genes. Zhou et al. (2007) reported an event of virulence acquisition through transposon insertion resulting in loss of resistance mediated by blast $R$ gene Pi-ta. M. oryzae is known to have multiple life cycles during a single crop season. Genetic variability of $M$. oryzae is predicted to be related with mutation, random genetic drift, gene flow, sexual reproduction, and selection pressure imposed by host $R$ genes (McDonald and Linde 2002).

The purpose of the present study was to examine genetic changes of the United States M. oryzae population collected
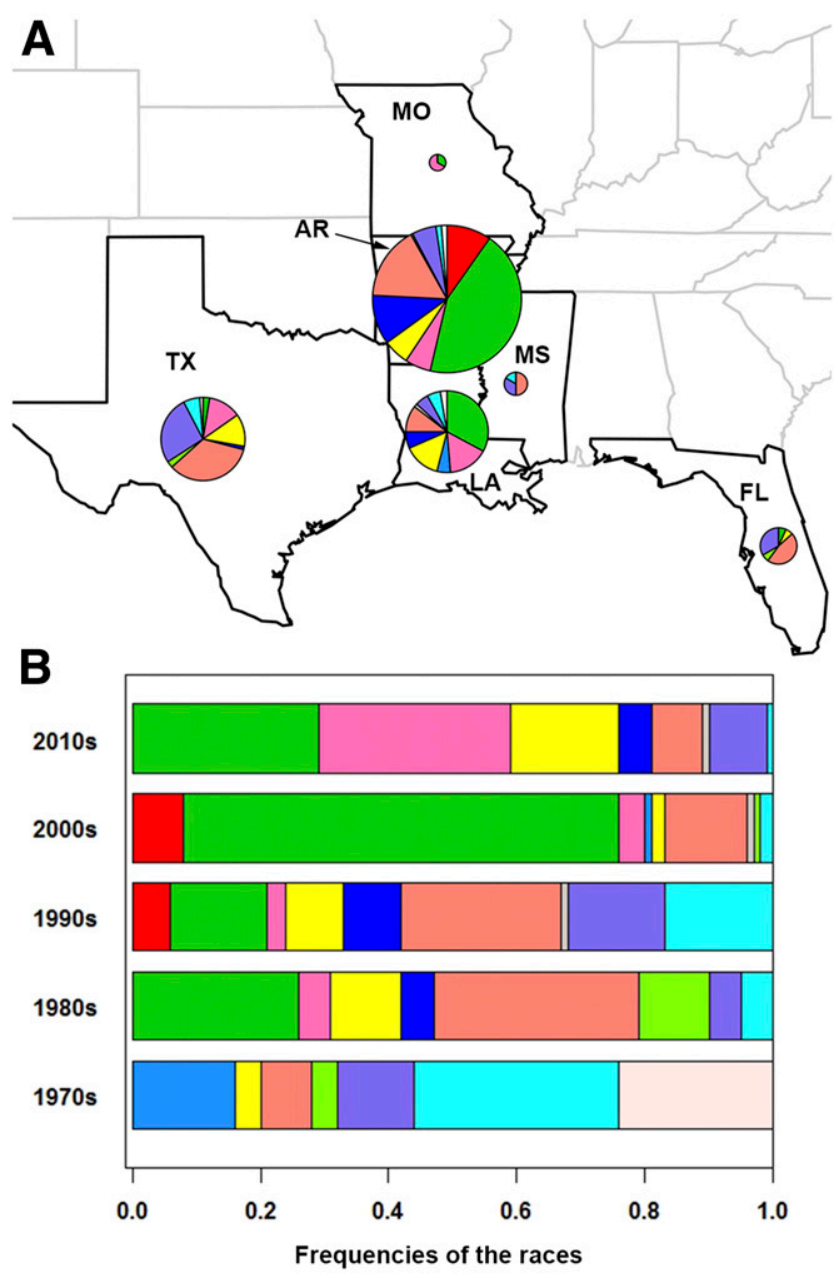

ㅁ IA_1 ㅁ IB_17 ㅁ IB_49 ㅁ IC_17 ㅁ ID_13 ㅁ IG_1

Fig. 1. Distribution of United States Magnaporthe oryzae races by locations and collection periods. A, A map of the southern United States indicating the distribution of races found in each rice-producing state. The size of each pie is proportionate to the number of races per number of isolates collected in each state. B, A segmented bar plot presenting the distribution of races in each decade. Note that numbers of resistant/avirulence gene interactions increase from the IA races through the IH race. The $x$ axis indicates frequency of each race and the $y$ axis specifies decade. Shades for each race in both bar and pie charts are shown in the legend. over several decades and to identify robust $R$ genes that can be used to enhance blast resistance in rice varieties. Specifically, we examined i) $M$. oryzae virulence acquisition, ii) genotypic diversity of simple sequence repeat (SSR) markers, iii) ecological differentiation, iv) asexual reproduction of $M$. oryzae in rice paddies, v) $M$. oryzae population structure, vi) temporal differentiation of the $M$. oryzae populations, and vii) relationship between pathogenicity, collection period, and genetic clusters of the $M$. oryzae population.

\section{RESULTS}

\section{M. oryzae virulence acquisition.}

We characterized 1,022 isolates consisting of 443 isolates from Arkansas, 201 from Louisiana, 174 from Texas, 49 from California, 36 from Florida, 23 from Mississippi, and five from Missouri (Supplementary Table S1). The earliest sample collection was from 1959. Analysis of the samples based on several decades (1950s, 1960s, 1970s, 1980s, 1990s, 2000s, and 2010s) showed that the largest collection period was in the 1990s, with 503 isolates consisting of 162 isolates from Arkansas, 131 from Texas, 54 from Louisiana, 49 from California, and 32 from Florida (Supplementary Fig. S1); the second largest collection of 329 isolates in the 2010s was 166 from Arkansas, 133 from Louisiana, 26 from Texas, and four from Missouri.

Analysis of 581 selected samples with IRD identified 39 races (Supplementary Table S2). IB-1, IC-17, and IB-49 were the most common races in Arkansas; IB-1, IB-17, and IB-49 in Louisiana; and IC-17, IE-1, and IB-49 in Texas (Fig. 1A). Only two isolates were collected in 1996 and 47 isolates were collected in 1997 that were determined to be the IG-1. The predominant races also varied among each decade. IB-45 (avirulence $[A V R]$ gene on four of eight differentials), IG-1 (AVR on six of eight), and IH-1 (AVR on seven of eight) were the top three most common races in the 1970s (Supplementary Table S3); IB-1, IC-17, and IB-49 in the 1980s; IC-17, IG-1, and IB-1 in the 1990s; and IB-1, IC-17, and IA-1 in the 2000s. Recently, from 2013 to 2015, races IB-17 (AVR on two of eight), IB-1 ( $A V R$ on one of eight), and IB-49 (AVR on three of eight) were relatively predominant (Fig. 1B). These results suggest that rice blast populations in the United States have shifted toward races with fewer $A V R$ genes throughout the past 60 years.

\section{Genotypic diversity of SSR markers in the United States M. oryzae population.}

To determine genetic diversity, $457 \mathrm{M}$. oryzae isolates were selected and analyzed with 10 polymorphic SSR markers (Supplementary Table S4). To examine the ability of the markers to detect sufficient genetic variation, we evaluated marker allele number and size, frequency of major alleles, polymorphism information content (PIC) (Botstein et al. 1980), $H_{\mathrm{e}}$ (Nei and Roychoudhury 1974), and evenness (EV) (Table 1; Supplementary Fig. S2). We detected a total of 87 marker alleles with 10 polymorphic markers in 457 isolates; however, 43 of them were detected less than $1 \%$. The range of allele numbers of each marker was from two to 14. Among them, markers pyrms 47-48 and pyrms 409-410, detecting 14 alleles, were the most polymorphic loci, whereas marker pyrms 63-64, detecting only two alleles, was the least polymorphic locus. The most predominant allele, 147 bp from pyrms 63-64, was detected in $93 \%$ of tested $M$. oryzae isolates. The PIC value varied from 0.14 (pyrms 63-64) to 0.90 (pyrms 43-44), with an average of 0.55 per locus. Seven SSR markers were highly informative (PIC $\geq 0.5)$, three were medium $(0.25<\mathrm{PIC}<0.5)$, and only one was low $(\mathrm{PIC}<0.25) . H_{\mathrm{e}}$ shared the same trends as PIC for each locus. The largest $H_{\mathrm{e}}$ was at markers pyrms 43-44 and 
pyrms 47-48, with a value of 0.81. EV examined the frequencies of each allele of the marker in a given locus. $E V$ values varied from 0.40 to 0.81 , with an average of 0.66 . The greatest EV observed at locus pyrms 657-658 (0.81), although the PIC and $H_{\mathrm{e}}$ values were not the highest at this locus. The marker pyrms 409-410 detected the lowest $E V$ of 0.40 ; a 168-bp allele was found in $80 \%$ of the isolates, while the values of other alleles were very low at this locus. In fact, $96 \%$ of the 2010 s collection also contained allele $168 \mathrm{bp}$. These findings suggest that these 10 SSR markers are excellent tools to evaluate genetic diversity of United States M. oryzae populations.

\section{Ecological differentiation \\ of the United States M. oryzae population.}

To examine if ecological environments of different locations (Arkansas, Louisiana, Texas, Florida, Missouri, Mississippi, and California) shape the genetic differentiation of the United States $M$. oryzae population, we analyzed genotypes of the $M$. oryzae population with standard statistical methods (Table 2). The allele number $\left(N_{\mathrm{a}}\right)$ and unique allele specific for each location (private allele; $N_{\mathrm{p}}$ ) per locus in seven locations varied from 1 to 6.4 and 0 to 1.2, respectively. Arkansas had the highest allele number $\left(N_{\mathrm{a}}=6.6\right)$ and Texas had the highest unique (private) allele $\left(N_{\mathrm{p}}=1.2\right)$. The multilocus genotype (MLG) number is used to describe genetic richness in each haplotype. The number of expected MLG (eMLG) estimates the number of MLG for the same sample size from each location. The eMLG was 8.82 in Texas, 8.58 in Louisiana, 8.76 in Arkansas, and seven in both Mississippi and Florida, suggesting that genetic diversity of these locations were highly similar.

$E V$ is the measurement of distribution of genotype abundance, where a population with equally abundant genotypes yields a value equal to 1 and a population dominated by a single genotype is closer to 0 . The $E V$ values of isolates were 0.94 from Florida, 0.92 from Missouri, and 1.00 from Mississippi indicating that the frequency of each MLG was highly similar in these states. $E V$ values were lower in Texas (0.7), Louisiana (0.55), and Arkansas (0.49), indicating that some MLGs dominate in these locations. The pairwise fixation index $\left(F_{S T}\right)$ value is used to examine the relatedness of genetic structure of $M$. oryzae isolates among different locations. The lowest $F_{S T}$ value was 0.0059 between Arkansas and Missouri, suggesting that the M. oryzae isolates in Arkansas and Missouri are highly related, whereas the highest $F_{S T}$ value was 0.4808 between California and Missouri, suggesting that the M. oryzae population in California is genetically distinguishable from that in Missouri (Supplementary Table S5). The $F_{S T}$ between Texas and Arkansas, Arkansas and Louisiana, and Louisiana and

Table 1. Diversity of simple sequence repeat markers in the United States Magnaporthe oryzae population

\begin{tabular}{lccccc}
\hline Locus & $\begin{array}{c}\text { Allele no. of } \\
\text { each marker }\end{array}$ & $\begin{array}{c}\text { Major allele } \\
\text { frequency }\end{array}$ & PIC $^{\mathbf{a}}$ & $\boldsymbol{H}_{\mathbf{e}} \mathbf{b}^{\mathbf{b}}$ & $\mathbf{E V}^{\mathbf{c}}$ \\
\hline pyrms 233-234 & 9 & 0.51 & 0.61 & 0.57 & 0.73 \\
pyrms 37-38 & 3 & 0.82 & 0.30 & 0.28 & 0.66 \\
pyrms 409-410 & 14 & 0.80 & 0.35 & 0.33 & 0.40 \\
pyrms 427-428 & 9 & 0.62 & 0.59 & 0.58 & 0.51 \\
pyrms 43-44 & 13 & 0.26 & 0.90 & 0.81 & 0.74 \\
pyrms 47-48 & 14 & 0.31 & 0.82 & 0.81 & 0.71 \\
pyrms 607-608 & 8 & 0.56 & 0.58 & 0.56 & 0.75 \\
pyrms 63-64 & 2 & 0.93 & 0.14 & 0.12 & 0.51 \\
pyrms 657-658 & 4 & 0.67 & 0.46 & 0.44 & 0.81 \\
pyrms 77-78 & 11 & 0.31 & 0.76 & 0.75 & 0.80 \\
Mean & 8.7 & 0.58 & 0.55 & 0.53 & 0.66 \\
\hline
\end{tabular}

a Polymorphic information content.

b Nei's unbiased diversity indicates degree of polymorphism.

${ }^{c} \mathrm{EV}=$ evenness indicates measurement of distribution of genotype abundance.
Texas, accounting for $95 \%$ of the isolates in the subcollection, were $0.0209,0.0248$, and 0.0524 , respectively, indicating that the $M$. oryzae isolates from Arkansas were genetically closer to the isolates collected in both Louisiana and Texas. However, the isolates from Louisiana and Texas were more genetically diverse even though they were geographically closer to each other. The highest $H_{\mathrm{e}}$ diversity (0.64) was in the Mississippi population; conversely, there were only seven Mississippi isolates in our collection, which is not a good representative of genetic diversity of the $M$. oryzae population in Mississippi. We then focused on the isolates from Arkansas, Louisiana, and Texas, where sample sizes were large enough to indicate the diversity. $H_{\mathrm{e}}$ values were 0.62 in Texas, 0.52 in Arkansas and 0.42 in Louisiana, suggesting that $M$. oryzae populations in these locations are much more diverse and dynamic.

\section{Asexual M. oryzae reproduction in the fields.}

Genetic diversity of the United States $M$. oryzae populations is similar to those of the Southwest China, Laos, and north Thailand region (0.61), where sexual reproduction in M. oryzae occurred (Saleh et al. 2014). High genetic diversity may correlate with sexual reproduction resulting in independent chromosome assortment and recombination followed by linkage equilibrium (Couch et al. 2005). To examine if sexual reproduction had occurred in the United States $M$. oryzae population, the index of association $\left(I_{\mathrm{A}}\right)$ and standardized index of association $\left(\bar{r}_{D}\right)$ were calculated (Table 3; Supplementary Fig. S3). The significant levels of $I_{\mathrm{A}}$ and $\bar{r}_{D}$ differ from 0 , suggesting that $M$. oryzae isolates are asexually reproduced. In the present study, we found that the significant $P$ values for both $I_{\mathrm{A}}$ and $\bar{r}_{D}$ of all states of the United States were 0.001, indicating that the United States $M$. oryzae populations were reproducing asexually. To validate this result, we also calculated $I_{\mathrm{A}}$ and $\bar{r}_{D}$ of United States $M$. oryzae population after clone correction, to remove the samples with the same genotypes. Despite slight reductions of both $I_{\mathrm{A}}$ and $\bar{r}_{D}$ after clone correction, they are still significantly different from 0 (Table 3; Supplementary Fig. S4). Taken together, these findings suggest that United States M. oryzae populations were asexually advanced.

\section{The structure of the United States $M$. oryzae population.}

Both STRUCTURE (Bayesian model based) and discriminant analysis of principal components (DAPC; model free) were used to determine the number of clusters of the United States $M$. oryzae population. Results of STRUCTURE suggest

Table 2. Genetic diversity of the Magnaporthe oryzae population in each state

\begin{tabular}{lrrlrlllll}
\hline State & Size $^{\mathbf{a}}$ & $\boldsymbol{N}_{\mathbf{a}}^{\mathbf{b}}$ & $\boldsymbol{N}_{\mathbf{p}}{ }^{\mathbf{c}}$ & $\mathbf{M L G}^{\mathbf{d}}$ & $\mathbf{e M L G}^{\mathbf{e}}$ & $\mathbf{S E}^{\mathbf{f}}$ & $\mathbf{S I}^{\mathbf{g}}$ & $\mathbf{E V}^{\mathbf{h}}$ & $\boldsymbol{H}_{\mathbf{e}}^{\mathbf{i}}$ \\
\hline Texas & 57 & 6.4 & 1.2 & 37 & 8.82 & 0.99 & 0.97 & 0.70 & 0.62 \\
Louisiana & 140 & 5.1 & 0.3 & 66 & 8.58 & 1.07 & 0.96 & 0.55 & 0.42 \\
Arkansas & 237 & 6.6 & 1 & 95 & 8.76 & 1.04 & 0.97 & 0.49 & 0.52 \\
Mississippi & 7 & 2.9 & 0.1 & 7 & 7 & 0 & 1.00 & 1.00 & 0.64 \\
Florida & 8 & 2.8 & 0 & 7 & 7 & 0 & 0.96 & 0.94 & 0.57 \\
Missouri & 5 & 2.2 & 0 & 4 & 4 & 0 & 0.90 & 0.92 & 0.48 \\
California & 3 & 1 & 0.1 & 1 & 1 & 0 & 0.00 & NaN & 0 \\
Total & 457 & 27 & 2.7 & 175 & 9.13 & 0.90 & 0.98 & 0.45 & 0.53 \\
\hline
\end{tabular}

${ }^{a}$ Sample size in each population.

b $N_{\mathrm{a}}=$ Mean number of alleles per locus.

c $N_{\mathrm{p}}=$ Mean number of private alleles per locus.

d Number of multilocus genotypes (MLG).

e The number of expected MLG at the smallest sample size $\geq 10$, based on rare faction.

f $\mathrm{SE}=$ standard error, based on eMLG.

g $\mathrm{SI}=$ Simpson's index.

${ }^{\text {h }} E V=$ Evenness.

${ }^{\mathrm{i}} H_{\mathrm{e}}=$ Nei's unbiased gene diversity. 
that the United States $M$. oryzae population could be divided into three clusters based on the delta $Q$ value (Supplementary Fig. S5A). However, obvious variations of the delta Bayesian information criterion (BIC) value were observed in the first six clusters. After six, the delta BIC values between the neighboring clusters were undistinguishable, indicating that the $M$. oryzae population could be separated into six clusters (Fig. 2 C). We then picked up the cluster results at Q6 based on STRUCTURE and compared Q3 and Q6 clustering.

To validate if the genetic clustering determined by STRUCTURE represents the maximal variations between clusters and minimal variations within each cluster, the DAPC approach was used. A total of 60 principal components (PCs) were initially used to capture nearly $100 \%$ of the genetic variation (Supplementary Fig. S6). Only five PCs were found to represent major genetic variation (Supplementary Fig. S7). To understand the evolutionary pathway, the neighbor-joining method was implemented to build an unrooted tree, using the pairwise genetic $H_{\mathrm{e}}$ between clusters (Fig. 3). The pie chart of each cluster indicates the proportion of isolates collected during the different time periods (Fig. 3; Supplementary Table S7). In general, clusters 2 and 6 contain only the isolates from the most recent decades (2000s and 2010s), of which $97 \%$ were collected in the 2010s, and cluster 5 contains the earliest isolates from the collection. Cluster 1 has $93 \%$ of its isolates collected from the 1990 s and 2000s, cluster 3 contains isolates from the 1970s to 2010s, and cluster 4 has isolates collected from the 1970s to 1990s. Since cluster 5 has the earliest isolates, subsequent isolates appeared to diverge into two directions. One direction formed cluster 1 and the other direction eventually diverged into two branches, one with clusters 2 and 3 and one with clusters 4 and 6 (Fig. 3). $F_{S T}$ was used to describe differential levels among the clusters. The least divergent clusters were clusters 2 and 3 and clusters 3 and 4 with an $F_{S T}$ of 0.20 (Table 4). The divergence between clusters 4 and 6 and clusters 2 and 4 was also low with an $F_{S T}$ of 0.25 and 0.29 , respectively. Those four clusters are located at the top and top right of Figure 2B. Although cluster 2 and 6 contained most of the recently collected isolates, they are genetically distant from each other with an $F_{S T}$ value equal to 0.56 , suggesting that contemporary isolates in the 2010s may have evolved through different mechanisms. It is notable that the $F_{S T}$ values $(0.48$ to 0.62 , mean $=0.556$ ) between cluster 1 and other clusters were large and reached up to 0.62 between clusters 1 and 6 indicating that cluster 1 was well-distinguished from other clusters. The $F_{S T}$ values, ranging from 0.39 to 0.48 , with mean $=0.448$, between cluster 5 and the other clusters were similar.

To characterize diversity and $E V$ of the $M$. oryzae subpopulations, the $H_{\mathrm{e}}$ value was calculated. It was noticed that $H_{\mathrm{e}}$ values were higher in clusters 3,4 , and $5,0.23,0.38$, and 0.45 ,

Table 3. Linkage disequilibrium analysis of simple sequence repeat profiles of the United States Magnaporthe oryzae populations ${ }^{\mathrm{a}}$

\begin{tabular}{|c|c|c|c|c|c|c|c|c|}
\hline \multirow[b]{2}{*}{ State } & \multicolumn{4}{|c|}{ Entire population } & \multicolumn{4}{|c|}{ Clone corrected } \\
\hline & $I_{\mathrm{A}}$ & $P I_{\mathrm{A}}$ & $\overline{\boldsymbol{r}}_{\mathbf{D}}$ & $\boldsymbol{P} \bar{r}_{\mathrm{D}}$ & $I_{\mathrm{A}}$ & $P I_{\mathrm{A}}$ & $\overline{\boldsymbol{r}}_{\mathbf{D}}$ & $\boldsymbol{P} \overline{\boldsymbol{r}}_{\mathbf{D}}$ \\
\hline Texas & 19 & 0.001 & 36 & .001 & 2.88 & 0.001 & 0 & 0.001 \\
\hline Louisiana & .39 & 0.001 & 0.29 & 0.001 & 1.81 & 0.001 & 0.21 & 0.001 \\
\hline Arkansas & 2.40 & 0.001 & 0.27 & 0.001 & 2.07 & 0.001 & 0.23 & 0.001 \\
\hline Mississippi & 2.45 & 0.001 & 0.28 & 0.001 & 2.45 & 0.001 & 0.28 & 0.001 \\
\hline Florida & 3.51 & 0.001 & 0.39 & 0.001 & 2.96 & 0.001 & 0.33 & 0.001 \\
\hline Missouri & 4.58 & 0.001 & 0.58 & 0.001 & 3.84 & 0.002 & 0.56 & 0.002 \\
\hline California & - & - & - & - & - & - & - & - \\
\hline
\end{tabular}

${ }^{\mathrm{a}} I_{\mathrm{A}}=$ index of association; $P=$ probability; $\bar{r}_{D}=$ the standardized index of association. respectively, when isolates were collected over several decades (Table 4). Within recently diverged clusters 2 and 6 , the $H_{\mathrm{e}}$ values were 0.17 and 0.13 , respectively. The lowest $H_{\mathrm{e}}$ value was observed in cluster 1 (0.06). EV analysis suggests that the distribution of haplotypes was more even in cluster $5(0.92)$ and less even in cluster $1(0.37)$.

\section{Temporal differentiation}

\section{of the United States $M$. oryzae populations.}

To verify if genetic differences were related to collection period, we combined samples within the same decade as subpopulations. Genetic distances within subpopulations and between subpopulations were calculated and projected on a twodimensional graph with DAPC (Fig. 4). The first discriminant function ( $x$ axis) separated $90 \%$ of the isolates in the 2010s from the others, while the second discriminant function ( $y$ axis) separated most of isolates in the 1990s and 2000s from those from the 1960s and 1970s. The isolates from the 1960s were separated further from the others, with the exception of one isolate from the $2000 \mathrm{~s}$, and a divergence point of the $M$. oryzae population was observed in the 1970s. After the 1970s, one M. oryzae group predominated in the 2010 s collection and another group predominated in 1990s (Fig. 4). These findings suggest that the United States $M$. oryzae population has evolved with little constraint over time. We then analyzed molecular variation (AMOVA) to determine if genomic differences occurred within or between populations. AMOVA revealed that there was more genomic diversity within isolates in different periods $(78.66 \%)$ than among periods $(29.13 \%)$ and among states $(-7.79 \%)$ (Table 5$)$.

\section{Relationship between pathogenicity, collection period, and genetic clusters of $M$. oryzae population.}

To determine if race identity of $M$. oryzae isolates was related to genetic diversity, we analyzed race distribution within the clusters (Fig. 5; Supplementary Table S8). First, we compared the races of $M$. oryzae isolates in clusters 2 and 3 and clusters 3 and 4 , which are genetically closely related. It was noticed that clusters 2 and 3 contained almost similar races; with 35 and $49 \%$ IB-1 isolates and 76 and $15 \%$ IB-17 isolates, respectively. However, $57 \%$ of cluster 3 isolates were in the IB group versus $8 \%$ of cluster 4 isolates; $19 \%$ of the cluster 3 isolates were in the IC group versus $52 \%$ of cluster 4 isolates. We then analyzed the recent $M$. oryzae collection in clusters 2 and 6 . Cluster 2 contained 31 IB-17 and 13 IB-1 isolates, accounting for 51 and $21 \%$, respectively. Cluster 2 contained only one IE- 1 isolate, in contrast to cluster 6 , which contained 12 IE-1 isolates accounting for $35 \%$ of the $M$. oryzae isolates and only a few M. oryzae isolates of race IB-17 or IB-1. An additional eight isolates in cluster 6 belonging to five IA race groups were identified, indicating that more virulent blast isolates existed in this cluster, because $M$. oryzae race IA was more virulent than the other races. Taken together, these data suggest that genetic differentiation of United States $M$. oryzae populations occurred between clusters related with collection periods and with pathogenicity.

\section{DISCUSSION}

In the present study, a total of 1,022 M. oryzae isolates collected in the past 56 years in the United States was characterized to understand the mechanism of adaptive genetic changes of the fungus and to develop strategies to enhance resistance to rice blast disease. To our knowledge, this is the first study of $M$. oryzae populations over multiple decades. We showed that $H_{e}$ was 0.53 representing the 457 isolates (Table 2). Our results are consistent with a previous study with $M$. oryzae isolates 
from the United States collected in the 2000s, with a $H_{\mathrm{e}}$ of 0.58 with 37 isolates (Saleh et al. 2014). Genetic diversity within the United States $M$. oryzae population was highly similar to isolates from Yunnan province, as one of the origins of cultivated rice (Saleh et al. 2014), and higher than the average diversity reported in a $M$. oryzae collection $(0.19 \pm 0.16$, ranging from 0 to 0.629 ) consisting of isolates from 15 countries, including 76 isolates from the United States. Multiple stochastic introductions of the M. oryzae pathogen in the United States are one of the most plausible explanations for the observed genetic diversity. Another likely explanation for the higher levels of diversity in the United States $M$. oryzae field collection is that the world-wide collection was from recent years (Saleh et al. 2014), whereas, the United States $M$. oryzae population was collected over a 56-year period, indicating that the $M$. oryzae population has been evolving over time throughout the past six decades. Moreover, the $F_{S T}$ value of the $M$. oryzae population suggests that low diversity was detected between populations from the southern United States, illustrating that diversity of isolates did not correlate with their collection areas.

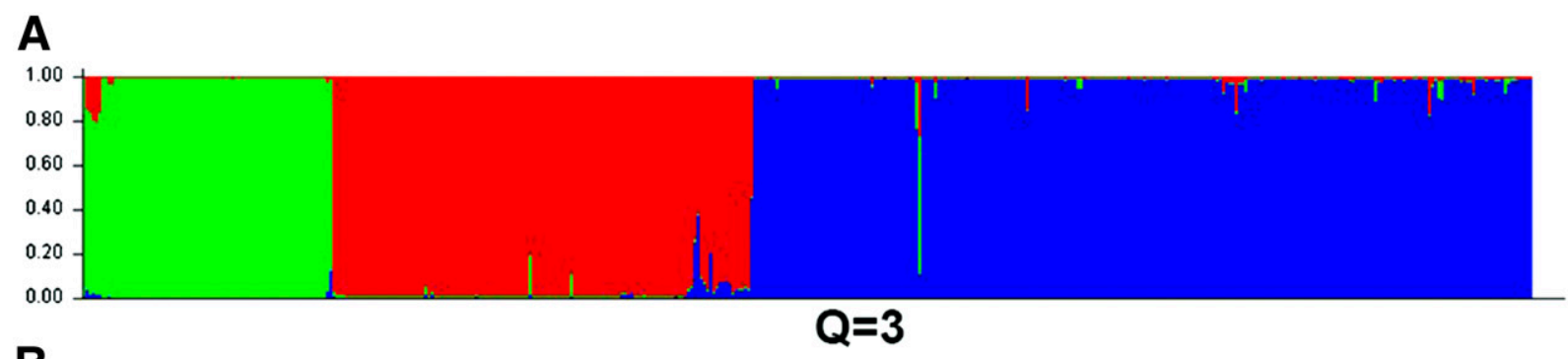

B

$Q=3$

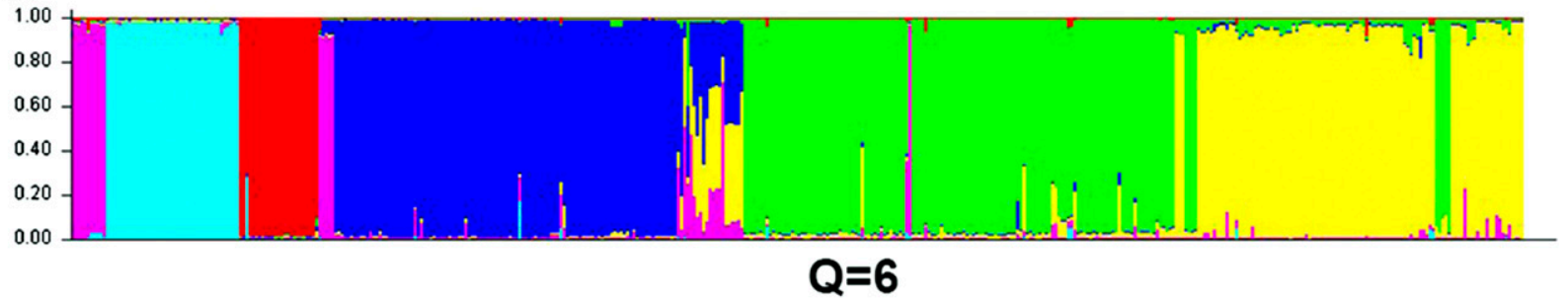

C

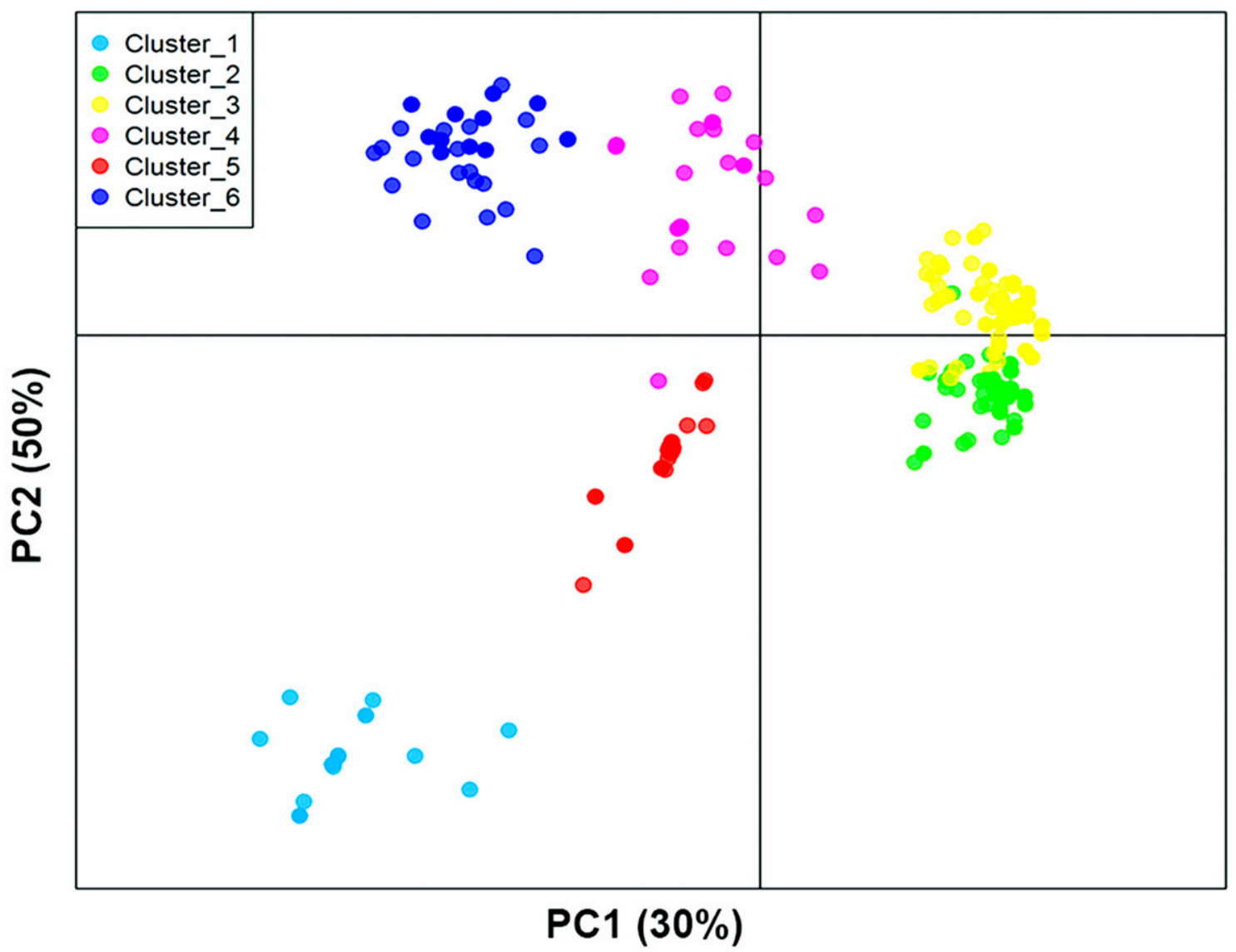

Fig. 2. STRUCTURE and discriminant analysis of principal components (DAPC) plots of genetic clusters of the United States Magnaporthe oryzae population. A, Visual representation of three clusters at $Q=3$. B, Visual representation of six clusters at $Q=6$. Subpopulation determined by STRUCTURE. C, Principal component plot of genetic groups determined with DAPC. The $x$ and $y$ axes indicate the first and second principal components, respectively. 
Our results on strains isolated in 1992 in Arkansas are also consistent with a previous report by Xia et al. (2000). Similarly, we found that all isolates collected from Arkansas in 1992 either belonged to IB-49 or IC-17. However, it is important to note that genetic identity of our isolates in IB-49 and IC-17 detected by SSRs were separated into different clusters compared with what Xia et al. (2000) reported. Levy et al. (1993) examined 115 isolates collected by the International Center for Tropical Agriculture's Santa Rosa experimental station, a known hot spot for blast, and identified six lineages with 39 races with greater diversity than that of United States isolates, suggesting a single lineage has different races and a single race was in various lineages (Levy et al. 1993). Xia et al. (1993) collected 113 isolates from two rice fields (cv. Newbonnet) in 1991, and concluded that, although certain fingerprint groups were composed of a single pathotype, other groups in the contemporary population were composed of isolates that are quite heterogeneous with respect to virulence. The $M$. oryzae isolates in the present study were from different states and cultivars over six decades; consequently, they were more diverse than the samples collected from the same region in a single year. Taken together, both lineage group and SSR are useful genetic markers for characterizing $M$. oryzae population.

$M$. oryzae isolates in the present study were not "evenly" collected from different states and time periods because each state differed in total areas of rice fields and occurrences of rice

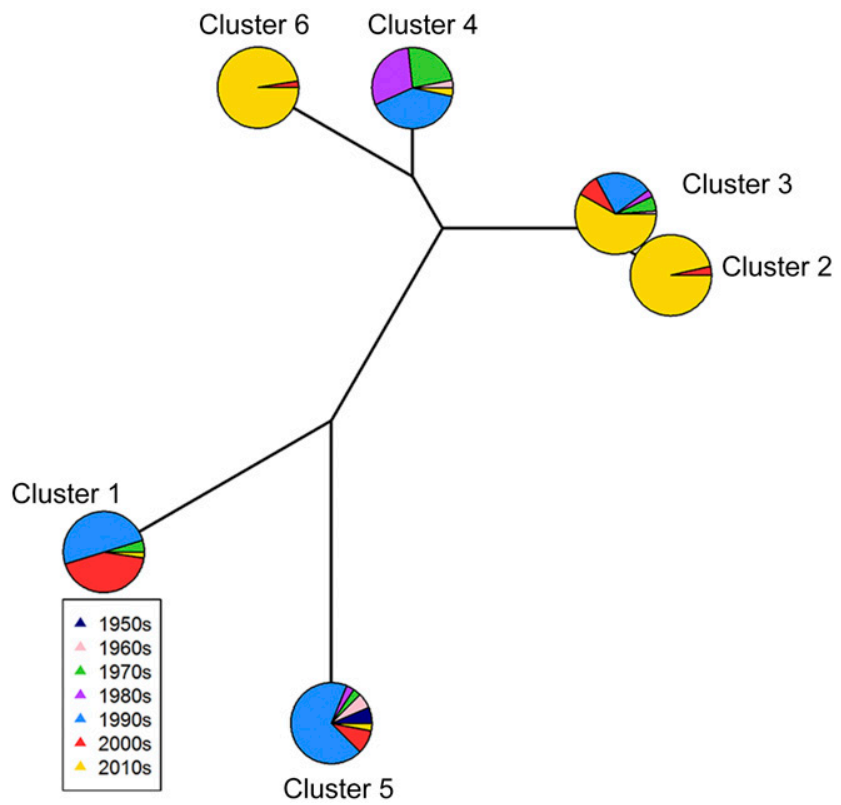

Fig. 3. Genetic cluster of the United States Magnaporthe oryzae population in an unrooted neighbor-joining tree. Pies at the end of each cluster indicate the proportion of samples collected from different time periods. Collection periods were indicated with different shades in the legend. blast disease each year during the past six decades. However, uneven sampling did not affect the conclusion of genetic shifts. The $H_{\mathrm{e}}$ value of $M$. oryzae isolates from each decade did not vary due to sample size, except for the 1950s because we only had two samples (Supplementary Table S9). Even though we only had four samples in the $1960 \mathrm{~s}$, unexpectedly, $H_{\mathrm{e}}$ was 0.633 , which is similar to that of the 2010s. Because we used eight rice differentials established in the 1960s (Atkins et al. 1967), the race identity being determined by disease reactions of a particular race or isolate on these rice differentials, we have an excellent indicator of virulence for $M$. oryzae populations over time. We showed that United States M. oryzae isolates have evolved, with the occurrence of more virulent races such as IA1 and IB1, over time (Fig. 1). As a matter of fact, most of the deployed rice varieties in Arkansas in the early decades possessed few major blast $R$ genes and, although more recent varieties possess one or more $R$ genes, all are susceptible to some races of rice blast (Lee 1994; K. Moldenhauer and A. McClung personal communications). Xia et al. (2000) demonstrated that some rice cultivars in the United States influenced the formation of certain genetic lineages of the $M$. oryzae population. The $A V R$ genes of the $M$. oryzae population are thought to be involved in pathogenicity and fitness (McDonald and Linde 2002). Virulence changes of $M$. oryzae populations are influenced by different $R$ genes, as deployed in new varieties. Change from avirulence to virulence is uncommon unless there are major blast $R$ genes deployed in the host in large areas and for an extended time. To rule out the possibility that deployed $R$ genes were the main reason for the genetic change of $M$. oryzae in United States commercial fields, we analyzed seven major $R$ genes, $P i-k m / s, P i-z, P i-t a / P i-t a 2, P i-d, P i-b$, $P i-a$, and $P i-i$, in United States rice cultivars deployed in the state of Arkansas, the major rice-growing state in the United States (Supplementary Fig. S8; Supplementary Table S10). Most of these major $R$ genes were deployed briefly and not in large acreages over the past six decades, except for $P i-\mathrm{km} / \mathrm{s}$. We showed that races IG-1, IH-1, and IB-54 were most commonly found in the 1960s and IB-45 in the 1970s (Fig. 2) (Marchetti et al. 1976). The $P i-\mathrm{km} / \mathrm{s}$ genes consist of two nucleotide binding site-leucine rich repeat protein members and different allelic combinations confer resistance to different races. $\mathrm{Pi}-\mathrm{km}$ confers resistance to the races IB-45, IB-54, IG-1, and IH-1, whereas $P i$-ks confers resistance to race IB54 (Marchetti et al. 1987; J. Wang et al. 2015). We found that $P i-\mathrm{km} / \mathrm{s}$ was in many commercial rice cultivars since the late 1960s. The $P i-\mathrm{km} / \mathrm{s}$ gene was predicted to engage in an arms race with $M$. oryzae AVR-Pik (Kanzaki et al. 2012; Van de Wouw et al. 2010; Wu et al. 2014). Numerous $M$. oryzae isolates belong to races IG-1, IH-1, IB-45, and IB-54 and have been recovered from $P i-\mathrm{km} / \mathrm{s}$ containing rice varieties over time. However, we have not identified multiple haplotypes of $A V R-P i \mathrm{~km} / \mathrm{s}$ in the recent decade in our survey (X. Wang and Y. Jia, unpublished data), suggesting that $\mathrm{Pi}-\mathrm{km} / \mathrm{s}$ may not impose high risk of evolution in United States $M$. oryzae populations.

Table 4. Pairwise genetic distance of United States Magnaporthe oryzae isolates based on the pairwise fixation index $\left(F_{S T}\right)$ matrix ${ }^{\mathrm{a}}$

\begin{tabular}{|c|c|c|c|c|c|c|c|c|c|c|}
\hline \multirow[b]{2}{*}{ Cluster } & \multirow[b]{2}{*}{$N$} & \multirow[b]{2}{*}{$N_{\mathbf{P}}$} & \multirow[b]{2}{*}{$\boldsymbol{H}_{\mathrm{e}}$} & \multirow[b]{2}{*}{$E V$} & \multicolumn{6}{|c|}{$F_{S T}$ matrix } \\
\hline & & & & & Cluster 1 & Cluster 2 & Cluster 3 & Cluster 4 & Cluster 5 & Cluster 6 \\
\hline 1 & 42 & 1 & 0.06 & 0.37 & 0.00 & & & & & \\
\hline 2 & 144 & 1 & 0.17 & 0.60 & 0.58 & 0.00 & & & & \\
\hline 3 & 99 & 0.98 & 0.23 & 0.81 & 0.56 & 0.20 & 0.00 & & & \\
\hline 4 & 30 & 0.97 & 0.38 & 0.76 & 0.54 & 0.29 & 0.20 & 0.00 & & \\
\hline 5 & 32 & 1 & 0.45 & 0.92 & 0.48 & 0.43 & 0.41 & 0.39 & 0.00 & \\
\hline 6 & 110 & 1 & 0.13 & 0.42 & 0.62 & 0.56 & 0.51 & 0.25 & 0.53 & 0.00 \\
\hline
\end{tabular}

${ }^{\text {a }} N=$ sample size in each population; $N_{\mathrm{P}}=$ mean number of private alleles per locus; $H_{\mathrm{e}}=$ Nei's unbiased gene diversity; $E V=$ evenness. 
The race $\mathrm{IC}-17$ became the more predominant isolate since the mid-1970s and IC-17 and IB-49 were more commonly found isolates in the mid-1980s (McClung 2002; Moldenhauer et al. 1992). The Pi-ta/Pi-ta2/Ptr(t) gene cluster confers resistance to most of the commonly found races including IB-49 and IC-17, except IE-1k. The Pi-ta/Pi-ta2/Ptr(t) gene cluster was widely used from the 1990 s to the 2000s. The loss of $A V R-$ Pital was first noted in 1993, with the identification of the race IE-1k. Pi-ta containing rice varieties Katy, Drew, and Kaybonnet were grown for a decade in Arkansas following this but were never devastated by IE-1k. However, IE-1k was responsible for the severe outbreak of blast on a $\mathrm{Pi}$-ta-containing variety Banks in 2004 (Correll et al. 2000; Lee et al. 2005; Zhou et al. 2007). Banks was developed by backcrossing strategies, unlike the other three Pi-ta-containing varieties, which suggests that additional blast $R$ genes or partial resistance in varieties Katy, Drew, and Kaybonnet may play important roles in resisting blast (K. Moldenhauer personal communication). Detailed analysis of $R$ genes in these $P i$ - $t a$-containing rice varieties will give us new clues of any roles that allelic combination may play in securing more stable blast resistance. Otherwise, it is also fully possible that the $M$. oryzae population without AVR-Pital was not predominant during that period of time. Xing et al. (2013) showed that most of isolates from the United States contain AVR-Pital, suggesting that AVR-Pital may be involved in fitness in the southern United States. Although more genetic changes occur in exon regions of the $\mathrm{Pi}$ - $\mathrm{ta}$ genes in rice and its wild relative population, unlike $P i-k$, only one resistant haplotype has been identified thus far (Huang et al. 2008; Lee et al. 2009; Wang et al. 2008). The discovery of 12 putative proteins suggests that $P i$ - $t a$ may have evolved a new

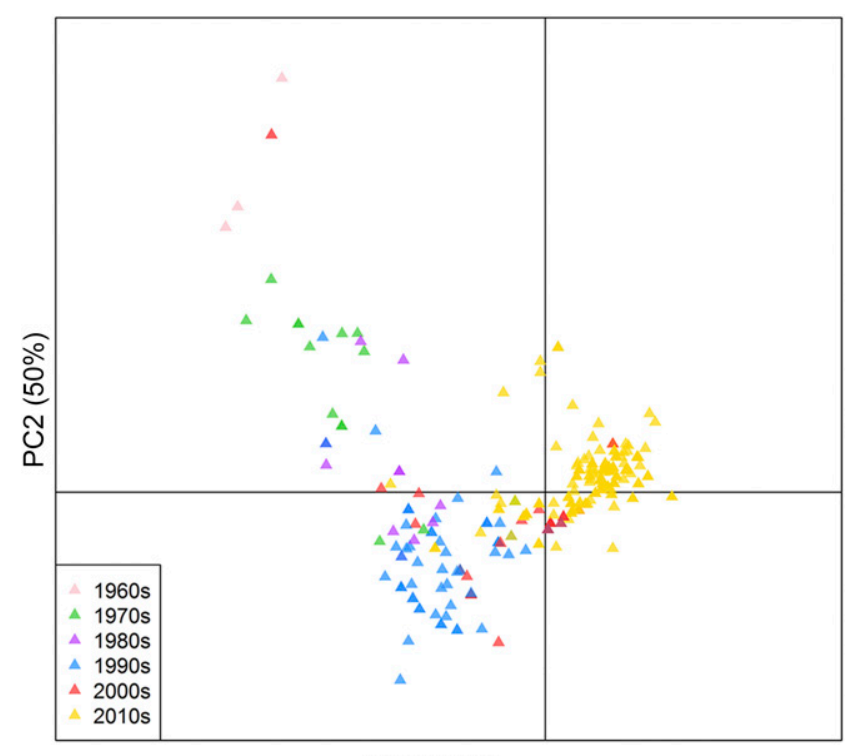

PC1 (30\%)

Fig. 4. Discriminant analysis of principal components graph of collection time periods. The $x$ and $y$ axes indicate the first and second discriminant analysis components, respectively. genetic mechanism to cope with AVR-Pital (Costanzo and Jia 2009).

Sexual reproduction of $M$. oryzae has been thought to be one of the common methods to evolve and adapt to host environment. Sexual reproduction was inferred in southwest China, Laos, north Thailand, and western Nepal (Saleh et al. 2014). In contrast, pathotype analysis in other rice production areas, such as Vietnam and Korea, revealed $M$. oryzae loci were in linkage disequilibrium (LD) suggesting asexual reproduction (Park et al. 2008; Thuan et al. 2006). Higher genetic diversity and lower LD are strong indicators of sexual reproduction in M. oryzae isolates (Onaga et al. 2015). Observed genetic diversity and virulence of United States $M$. oryzae isolates raised the question if the United States M. oryzae isolates were sexually reproducing. Previous studies demonstrated that the United States $M$. oryzae isolates were grouped in eight lineages (A through $\mathrm{H}$ ), all M. oryzae isolates in lineages A, D, E, G, and $\mathrm{H}$ had the mat $1-1$ allele, whereas isolates in lineages $\mathrm{B}, \mathrm{C}$, and $\mathrm{F}$ had the mat1-2 allele, suggesting that asexual reproduction exists in the United States M. oryzae populations (Correll et al. 2000). This finding is consistent with previous studies; the perfect association of independent markers in the present study suggests that United States $M$. oryzae isolates were asexually reproduced.

\section{Summary.}

In the present study, we analyzed 1,022 United States blast isolates collected from 1959 to 2015 , based on pathotype and genomic assays, to guide future $R$-gene deployment in the United States. A total of $39 \mathrm{M}$. oryzae races were identified. Among them, 17, with five most commonly found in recent years (Table 6), were recommended to identify effective blast $R$ genes. We also demonstrated that there are six genetic clusters in the United States M. oryzae isolates and the virulence of pathogen isolates has been increasing over the time through asexual reproduction. The observed gene clusters were not associated with geographic origin of the isolates but, rather, they were associated with collection time periods. These findings suggest that variations in host genotypes were responsible for rapid adaptation of rice blast fungus. The results and knowledge attained in these studies will benefit the identification of rice resistance genes for developing blast-resistant rice varieties. Our results also indicated that durable control of blast disease will require constant field monitoring to document dynamic population changes as they are happening.

\section{MATERIALS AND METHODS}

\section{Isolate collection, single spore purification, and conservation.}

The samples were not evenly distributed across years and locations because of the erratic occurrence of blast disease, loss in storage, and other uncontrollable events. A total of 1,022 M. oryzae isolates were purified from leaf, collar, or panicle samples. Symptomatic rice tissue samples were collected either from rice on experiment stations or in commercial rice fields from 1959 to 2015 during the regular rice-cropping season. The

Table 5. Analysis of molecular variance (AMOVA) of Magnaporthe oryzae isolates based on states of the United States ${ }^{\text {a }}$

\begin{tabular}{|c|c|c|c|c|c|c|c|}
\hline Hierarchy & Df & SS & MS & $\mathbf{V}$ & $\%$ & Phi & $P$ value \\
\hline Between states & 6 & 80.10 & 13.35 & -0.22 & -7.79 & -0.08 & 0.577 \\
\hline Between periods within states & 19 & 208.43 & 10.97 & 0.87 & 29.13 & 0.27 & 0.001 \\
\hline Within samples in each period & 431 & 950.72 & 2.21 & 2.21 & 78.66 & 0.21 & 0.001 \\
\hline Total & 456 & 1239.24 & 2.72 & 2.80 & 100 & & \\
\hline
\end{tabular}

${ }^{\mathrm{a}} \mathrm{Df}=$ degree of freedom; $\mathrm{SS}=$ sum square; $\mathrm{MS}=$ mean square; $\mathrm{V}=$ variance; $\%$ = percentage of variance in total variance. 
archived isolates from the 1950s to 1990s were collected from rice fields in Arkansas, Louisiana, Texas, Mississippi, Missouri, Florida, and California by T. Marchetti (United States Department of Agriculture Agricultural Research Service [USDAARS], Texas) and were transferred to the USDA-ARS Dale Bumpers National Rice Research Center, Stuttgart, Arkansas upon the closure of the ARS laboratory in Beaumont, Texas. The recent field blast isolates were only collected from experiment stations or commercial rice fields in Arkansas, Texas, Louisiana, and Missouri. No sample was collected from California after the 1990 s, due to contemporary quarantine restrictions.

A single-spore isolation method described by Jia (2009) was used to isolate and purify the rice blast fungus. Subsequently, the purified mycelia from a single spore were grown on sterilized filter paper superimposed on the surface of oatmeal agar medium. The mycelia and spores were left to colonize the entire filter paper. The filter papers with the fungal structures were then transferred to a desiccation chamber approximately 10 days after culturing. Desiccated filter papers with mycelia and spores were cut into small pieces $\left(0.5 \times 0.5 \mathrm{~cm}^{2}\right)$ and were stored in glass vials at $-20^{\circ} \mathrm{C}$.

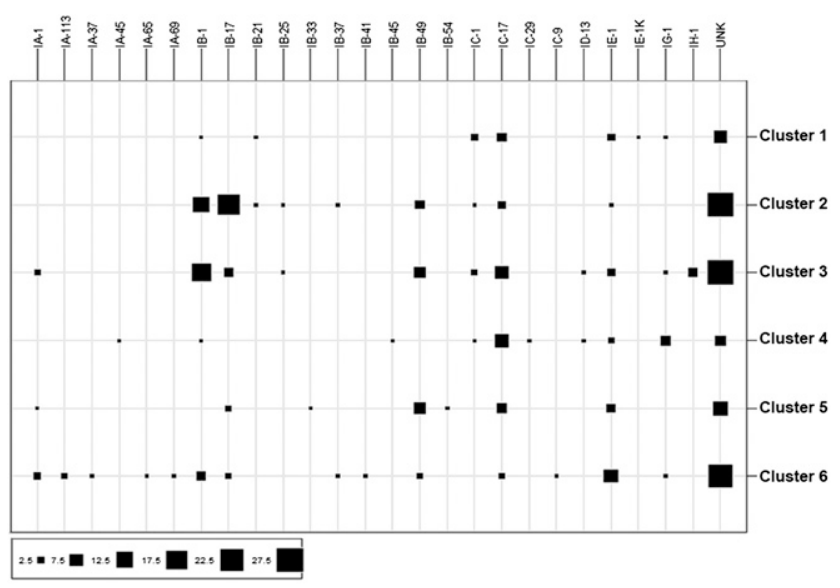

Fig 5. Distribution of races after clone correction in each cluster. The $x$ axis indicates races and the $y$ axis indicates cluster number. Rectangles indicate number of isolates in each race group found in each cluster scale at the bottom. UNK indicates race undetermined.

\section{Pathogenicity determination}

with eight international differential rice varieties.

Eight IRD varieties used were Raminad Str. 3, Zenith, NP125, Usen, Dular, Kanto 51, Sha-tiao-tsao, and Caloro (Ling and $\mathrm{Qu}$ 1969). The most virulent isolates that infected all eight rice differential varieties were grouped as IA1 and the least virulent isolates that did not infect all eight rice varieties were classified as II- 1 .

Eight to 10 seeds of each differential line were planted in black plastic inserts, with holes in the bottom $(3.8 \times 3.8 \times$ $7 \mathrm{~cm}^{3}$ ), containing greenhouse soil composed of sterilized silty clay soils. A tray containing these inserts was filled with water. The greenhouse was maintained under $8 \mathrm{~h}$ of light and $16 \mathrm{~h}$ of dark at room temperature (approximately $25^{\circ} \mathrm{C}$ ). Seedlings of the differential lines were inoculated with a spore suspension of each isolate at the three- to four-leaf stage. Methods described by X. Wang et al. (2015) for preparation of spore suspension, inoculation, and scoring disease were followed throughout the course of the experiment. Races were assigned to each isolate based on pathogenicity reactions of Raminad Str. 3, Zenith, NP-125, Usen, Dular, Kanto 51, Sha-tiao-tsao, and Caloro. For example, the isolate that was resistant to Raminad Str. 3, NP-125, and Usen but susceptible to the rest of the accessions belongs to race IB49.

\section{DNA extraction, polymorphic SSR marker evaluation, and genotyping.}

DNA extraction was performed following a protocol described by Jia et al. (2014). A total of 14 SSR markers were screened and 10 polymorphic SSR markers were identified. A total of 457 isolates randomly selected in each year and state were genotyped with these 10 SSR markers (Supplementary Table S11). PCR assays were run with a total volume of $25 \mu \mathrm{l}$, including $10 \mu \mathrm{l}$ of PCR buffer, $0.4 \mu \mathrm{l}$ of each primer, $0.5 \mu \mathrm{l}$ of bovine serum albumin, $0.4 \mu \mathrm{l}$ of polyvinylpyrrolidone, $4 \mu \mathrm{l}$ of DNA, $0.2 \mu \mathrm{l}$ of Taq polymerase, and $9.1 \mu \mathrm{l}$ of molecular grade water. Water was used as negative control. Reverse primers were unlabeled in order to reduce the cost and the forward primers were labeled with either 6FAM, NED, PET, or HEX (Integrated DNA Technologies, Coralville, IA, U.S.A., Applied Biosystems, Foster City, CA, U.S.A.). The PCR program was used as follows: i) predenature at $95^{\circ} \mathrm{C}$ for $3 \mathrm{~min}$, ii) denature at $95^{\circ} \mathrm{C}$ for $30 \mathrm{~s}$, iii) annealing at 55 to $61^{\circ} \mathrm{C}$ for $30 \mathrm{~s}$, iv) extension at $72^{\circ} \mathrm{C}$ for $30 \mathrm{~s}, \mathrm{v}$ ) repeat step 2 through 4 for 34 cycles, and vi) final extension at $72^{\circ} \mathrm{C}$ for $5 \mathrm{~min}$. PCR products were pooled

Table 6. Genetic identity and race information of recommended races and isolates of Magnaporthe oryzae for breeding for improved blast resistance

\begin{tabular}{|c|c|c|c|c|c|c|}
\hline Isolate & Source cultivars ${ }^{\mathrm{a}}$ & Genetic cluster $^{b}$ & Year of isolation & Races & State & Frequency of occurrence \\
\hline 14A24_1 & Caffey & 3 & 2014 & IC-17 & Arkansas & The most common race \\
\hline SSID_10 & CL 151 & 3 & 2013 & IB-25 & Arkansas & Uncommon race \\
\hline $15 \mathrm{~A} 6 \_3$ & CL 151 & 6 & 2015 & IB-1 & Arkansas & The most common race \\
\hline SSID_132 & CL 261 & 6 & 2013 & IA-37 & Arkansas & Uncommon race \\
\hline SSID_130 & CL 261 & 6 & 2013 & IA-65 & Arkansas & Uncommon race \\
\hline SSID_131 & CL 261 & 6 & 2013 & IA-69 & Arkansas & Uncommon race \\
\hline SSID_1 & CL 261 & 2 & 2012 & IB-17 & Arkansas & The most common race \\
\hline SSID_2 & CL 261 & 2 & 2012 & IB-49 & Arkansas & The most common race \\
\hline SSID_75 & CL 261 & 6 & 2012 & IC-9 & Arkansas & Uncommon race \\
\hline SSID_118 & CL 261 & 3 & 2013 & IE-1 & Arkansas & The most common race \\
\hline SSID_126 & CL 262 & 6 & 2013 & IB-41 & Arkansas & Uncommon race \\
\hline SSID_125 & Colorado & 2 & 2013 & IC-1 & Texas & Uncommon race \\
\hline 15A $1 \overline{6} \_1$ & Jupiter & 6 & 2015 & IA-1 & Arkansas & Uncommon race \\
\hline 15A5_2 & Jupiter & 6 & 2015 & IA-113 & Arkansas & Uncommon race \\
\hline SSID_124 & Jupiter & 2 & 2013 & IB-21 & Louisiana & Uncommon race \\
\hline SSID_13 & Jupiter & 6 & 2013 & IG-1 & Arkansas & Uncommon race \\
\hline SSID_45 & LA 2025 & 2 & 2013 & IB-37 & Louisiana & Uncommon race \\
\hline
\end{tabular}

${ }^{a}$ The cultivar from which fungi were isolated.

${ }^{\mathrm{b}}$ Genetic clusters determined based on simple sequence repeat profile with discriminant analysis of principal components. 
based on sizes of amplified fragments (typically three markers per run along with a LIZ-labeled size standard) to reduce the cost, and the DNA was denatured by heating samples at $94^{\circ} \mathrm{C}$ for $5 \mathrm{~min}$. PCR products were run on the ABI 3730 DNA analyzer and allele size was determined by GeneMapper version 3.7 (Applied Biosystems).

The marker diversity of SSR markers was analyzed to determine if these 10 selected SSRs represent enough diversity in the present $M$. oryzae population and could be reliable for future analysis. PIC was used to evaluate the diversity of SSR markers for population genetics studies. The formula to calculate the PIC value for each SSR is as described below (Anderson et al. 1993; Botstein et al. 1980), where Pi stands for the $i$ th allele frequency of one SSR locus. The formula, PIC = $1-\sum(\mathrm{Pi})^{2}$ was used to calculate the PIC value for each SSR (Anderson et al. 1993; Botstein et al. 1980), where Pi stands for the $i$ th allele frequency of one SSR locus.

\section{Genetic differentiation and distances between populations.}

To infer the unbiased genetic diversity $\left(H_{\mathrm{e}}\right)$, private allele size (allele size in each location) and the number of MLG were calculated using the package "poppr" in R package (Kamvar et al. 2014, 2015). The proportion of unique MLG in each population was calculated as the $G: N$ ratio, where $G$ is the number of MLG and $N$ is the number of isolates in each subpopulation. To determine population differentiation due to genetic structure, the hierfstat package in $\mathrm{R}$ was used to calculate $F_{S T}$. $E V$ measures how genotypes of $M$. oryzae are distributed within a population despite the populations differing in the number of genotypes (Arnaud-Haond et al. 2005). EV ranges from 0 to 1 , where 0 indicates all individuals in a $M$. oryzae population have the same genotype and 1 indicates all individuals have different genotypes occurring at the same frequency.

\section{Model of reproduction.}

Sexual reproduction is one of the critical ways to force recombination of genomic fragments in $M$. oryzae. LD is commonly used to examine if $M$. oryzae is clonally or sexually reproduced. To determine the model of $M$. oryzae reproduction, the poppr package of $\mathrm{R}$ was used to determine the LD of SSR-based genotypes. Clone correction in poppr was used to ensure only one isolate per MLG represented per population (Grünwald and Hoheisel 2006; Grünwald et al. 2003; Milgroom 1996). If the alleles observed at different loci are not linked, it meant that $M$. oryzae populations are under sexual reproduction. The $I_{\mathrm{A}}$ and the $\bar{r}_{\mathrm{D}}$ were used to assess if loci were linked. The difference between $I_{\mathrm{A}}$ and $\bar{r}_{D}$ is that the latter is less biased. An IA and $\bar{r}_{D}$ equal to 0 indicate a perfect equilibrium of the loci suggesting that a $M$. oryzae population reproduces sexually.

\section{Cluster determination.}

We first used the Bayesian method in STRUCTURE software to determine the most plausible population group number (Falush et al. 2003; Pritchard et al. 2000). Q of the Bayesian method ranged from 1 to 10 , with 10 replicates for each Q. For each run, a 10,000-step Monte Carlo Markov chain was performed after a 10,000 steps burn-in period. We determined the optimal number of clusters (Q) to capture the overall genetic variation of $M$. oryzae population according to Evanno et al. (2005). DAPC in the "Adegenet" package of R (v2.0.1) (Jombart and Ahmed 2011, Jombart 2008, 2010) was then used to validate the population groups determined by STRUCTURE. The K-means procedure was implemented in the function 'find. clusters' to infer the optimal number of clusters maximizing the variation between clusters (Jombart and Collins 2015) Cluster number determined with the BIC value and the assigned probability of each isolate is listed in Supplementary Table S12.

\section{ACKNOWLEDGMENTS}

This project is supported by Agriculture and Food Research Initiative Competitive grant number 2013-68004-20378 (Blast Integrated Project [BIP]) from the United States Department of Agriculture (USDA) National Institute of Food and Agriculture, and USDA-Agricultural Research Service (ARS) NP301 in house project. We thank D. Groth (Louisiana State University, Baton Rouge), X.-G. Zhou (Texas A\&M Agrilife, Beaumont, TX, U.S.A.), A. McClung (USDA-ARS Dale Bumpers National Rice Research Center [DB NRRC], Stuttgart, AR, U.S.A.), T. Gebremariam, T. Mulaw (University of Arkansas Cooperative Extension Service), and T. Bianco and T. Sookaserm (USDA-ARS DB NRRC) for collecting blast isolates in the rice fields and technical assistance; M. Hodges, H. Herald, and T. Franzen (University of Arkansas Rice Research and Extension Center [UA RREC], Stuttgart) for assisting in $M$. oryzae storage and inoculation; and M. Lin (USDA-ARS DB NRRC and UA RREC) for blast evaluation and collection, and many other agents in the southern United States for collecting blast samples from other locations. For blast isolate purification and analysis from 1960 to 2000, we thank T. Marchetti (retired from USDA ARS-Rice Research Unit, Beaumont and now deceased). We also thank F. Chumley for his role as the project coordinator for BIP. This is contribution number 17-330-J from the Kansas Agricultural Experiment Station. The USDA is an equal opportunity provider and employer.

\section{LITERATURE CITED}

Anderson, J. A., Churchill, G. A., Autrique, J. E., Tanksley, S. D., and Sorrells, M. E. 1993. Optimizing parental selection for genetic linkage maps. Genome 36:181-186.

Arnaud-Haond, S., Alberto, F., Teixeira, S., Procaccini, G., Serrão, E. A., and Duarte, C. M. 2005. Assessing genetic diversity in clonal organisms: Low diversity or low resolution? Combining power and cost efficiency in selecting markers. J. Hered. 96:434-440.

Atkins, J. G., Robert, A. L., Adair, C. R., Goto, K., Kozaka, T., Yanagida, R., Yamada, M., and Matsumoto, S. 1967. An international set of rice varieties for differentiating races of Piricularia oryzae. Phytopathology 57:297-301.

Botstein, D., White, R. L., Skolnick, M., and Davis, R. W. 1980. Construction of a genetic linkage map in man using restriction fragment length polymorphisms. Am. J. Hum. Genet. 32:314-331.

Chen, D., Zeigler, R. S., Leung, H., and Nelson, R. J. 1995. Population structure of Pyricularia grisea at two screening sites in the Philippines. Phytopathology 85:1011-1020.

Chen, Q. H., Wang, Y. C., and Zheng, X. B. 2006. Genetic diversity of Magnaporthe grisea in China as revealed by DNA fingerprint haplotypes and pathotypes. J. Phytopathol. 154:361-369.

Correll, J. C., Harp, T. L., Guerber, J. C., Zeigler, R. S., Liu, B., Cartwright, R. D., and Lee, F. N. 2000. Characterisation of Pyricularia grisea in the United States using independent and molecular markers. Phytopathology 90:1396-1404.

Costanzo, S., and Jia, Y. 2009. Alternatively spliced transcripts of $\mathrm{Pi}$-ta blast resistance gene in Oryza sativa. Plant Sci. 177:468-478.

Couch, B. C., Fudal, I., Lebrun, M. H., Tharreau, D., Valent, B., van Kim, P., Nottéghem, J. L., and Kohn, L. M. 2005. Origins of host-specific populations of the blast pathogen Magnaporthe oryzae in crop domestication with subsequent expansion of pandemic clones on rice and weeds of rice. Genetics 170:613-630.

Don, L. D., Kusaba, M., Urashima, A. S., Tosa, Y., Nakayashiki, H., and Mayama, S. 1999. Population structure of the rice blast fungus in Japan examined by DNA fingerprinting. Ann. Phytopathol. Soc. Jpn. 65:15-24.

Evanno, G., Regnaut, S., and Goudet, J. 2005. Detecting the number of clusters of individuals using the software STRUCTURE: A simulation study. Mol. Ecol. 14:2611-2620.

Falush, D., Stephens, M., and Pritchard, J. K. 2003. Inference of population structure using multilocus genotype data: Linked loci and correlated allele frequencies. Genetics 164:1567-1587.

Grünwald, N. J., Goodwin, S. B., Milgroom, M. G., and Fry, W. E. 2003. Analysis of genotypic diversity data for populations of microorganisms. Phytopathology 93:738-746.

Grünwald, N. J., and Hoheisel, G. A. 2006. Hierarchical analysis of diversity, selfing, and genetic differentiation in populations of the oomycete Aphanomy ceseuteiches. Phytopathology 96:1134-1141. 
Huang, C. L., Hwang, S. Y., Chiang, Y. C., and Lin, T. P. 2008. Molecular evolution of the Pi-ta gene resistant to rice blast in wild rice (Oryza rufipogon). Genetics 179:1527-1538.

Jia, Y. 2009. A user-friendly method to isolate and single spore the fungi Magnaporthe oryzae and Magnaporthe grisea obtained from diseased field samples. Plant Health Prog. Published online. doi:10.1094/PHP2009-1215-01-BR

Jia, Y., Wamishe, Y. A., and Zhou, B. 2014. An expedited method to isolate DNA for PCR from Magnaporthe oryzae stored on filter paper. Crop J. 2: 267-271.

Jombart, T. 2008. adegenet: A R package for the multivariate analysis of genetic markers. Bioinformatics 24:1403-1405.

Jombart, T., and Ahmed, I. 2011. adegenet 1.3-1: New tools for the analysis of genome-wide SNP data. Bioinformatics 27:3070-3071.

Jombart, T., and Collins, C. 2015. A tutorial for discriminant analysis of principal components (DAPC) using adegenet 2.0.0. MRC Centre for Outbreak Analysis and Modelling, Imperial College, London. http:// adegenet.r-forge.r-project.org/files/tutorial-dapc.pdf. Published online.

Jombart, T., Devillard, S., and Balloux, F. 2010. Discriminant analysis of principal components: A new method for the analysis of genetically structured populations. BMC Genet. 11:94.

Kamvar, Z. N., Brooks, J. C., and Grünwald, N. J. 2015. Novel R tools for analysis of genome-wide population genetic data with emphasis on clonality. Front. Genet. 6:208.

Kamvar, Z. N., Tabima, J. F., and Grünwald, N. J. 2014. Poppr: An R package for genetic analysis of populations with clonal, partially clonal, and/or sexual reproduction. PeerJ 2:e281.

Kanzaki, H., Yoshida, K., Saitoh, H., Fujisaki, K., Hirabuchi, A., Alaux, L., Fournier, E., Tharreau, D., and Terauchi, R. 2012. Arms race coevolution of Magnaporthe oryzae AVR-Pik and rice Pik genes driven by their physical interactions. Plant J. 72:894-907.

Kumar, J., Nelson, R. J., and Zeigler, R. S. 1999. Population structure and dynamics of Magnaporthe grisea in the Indian Himalayas. Genetics 152:971-984.

Lee, F. N. 1994. Rice breeding programs, blast epidemics and blast management in the United States. Pages 489-500 in: Rice Blast Disease. R. S. Zeigler, S. Leong, and P. S. Teng, eds. Commomw. Agric.Buri. Int, Willingford, U.K.

Lee, F. N., Cartwright, R. D., Jia, Y., Correll, J. C., Moldenhauer, K. A. K., Gibbons, J. W., Boyett, V., Zhou, E., Boza, E., and Seyran, E. 2005. A preliminary characterization of the rice blast fungus on 'Banks' rice. Pages 103-110 in: B. R. Wells Rice Research Studies 2004. No. 529. R. J. Norman, J.-F. Mullenet, and K. A. K. Moldenhauer, eds. University of Arkansas Agricultural Experiment Station Research Service. http://www. uark.edu/depts/agripub/Publications/researchseries

Lee, S., Costanzo, S., Jia, Y., Olsen, K. M., and Caicedo, A. L. 2009. Evolutionary dynamics of the genomic region around the blast resistance gene Pi-ta in AA genome Oryza species. Genetics 183:1315-1325.

Levy, M., Correa-Victoria, F. J., Zeigler, R. S., Xu, S., and Hamer, J. E. 1993. Genetic diversity of the rice blast fungus in a disease nursery in Colombia. Phytopathology 83:1427-1433.

Levy, M., Romao, J., Marchetti, M. A., and Hamer, J. E. 1991. DNA fingerprinting with a dispersed repeated sequence resolves pathotype diversity in the rice blast fungus. Plant Cell 3:95-102.

Ling, K. C., and Qu, S. H. 1969. Standardization of the international race numbers of Pyricularia oryzae. Phytopathology 59:339-342.

Marchetti, M. A. 1983. Dilatory resistance to rice blast in USA rice. Phytopathology 73:645-649.

Marchetti, M. A., Lai, X., and Bollich, C. N. 1987. Inheritance of resistance to Pyricularia oryzae in rice cultivars grown in the United States. Phytopathology 77:799-804.

Marchetti, M. A., Rush, M. C., and Hunter, W. E. 1976. Current status of rice blast in the southern United States. Plant Dis. Rep. 60:721-725.

McClung, A. M. 2002. Techniques for development of new cultivars. Pages 177-202 in: Rice: Origin, History, Technology, and Production. C. W. Smith, and R. H. Dilday, eds. John Wiley \&Sons, Inc., Hoboken, NJ.

McDonald, B. A., and Linde, C. 2002. Pathogen population genetics, evolutionary potential, and durable resistance. Annu. Rev. Phytopathol. 40:349-379.
Milgroom, M. G. 1996. Recombination and the multilocus structure of fungal populations. Annu. Rev. Phytopathol. 34:457-477.

Moldenhauer, K. A. K., Bastawisi, A. O., and Lee, F. N. 1992. Inheritance of resistance in rice to races IB-49 and IC-17 of Pyricularia oryzae rice blast. Crop Sci. 32:584-588.

Nalley, L., Tsiboe, F., Durand-Morat, A., Shew, A., and Thoma, G. 2016. Economic and environmental impact of rice blast pathogen (Magnaporthe oryzae) alleviation in the United States. PLoS One 11: e0167295.

Nei, M., and Roychoudhury, A. K. 1974. Sampling variances of heterozygosity and genetic distance. Genetics 76:379-390.

Onaga, G., Wydra, K., Koopmann, B., Séré, Y., and von Tiedemann, A. 2015. Population structure, pathogenicity, and mating type distribution of Magnaporthe oryzae isolates from east Africa. Phytopathology 105: 1137-1145.

Park, S. Y., Milgroom, M. G., Han, S. S., Kang, S., and Lee, Y. H. 2008. Genetic differentiation of Magnaporthe oryzae populations from scouting plots and commercial rice fields in Korea. Phytopathology 98:436-442.

Pritchard, J. K., Stephens, M., and Donnelly, P. 2000. Inference of population structure using multilocus genotype data. Genetics 155 : 945-959.

Saleh, D., Milazzo, J., Adreit, H., Fournier, E., and Tharreau, D. 2014. South-East Asia is the center of origin, diversity and dispersion of the rice blast fungus, Magnaporthe oryzae. New Phytol. 201: $1440-1456$

Thuan, N. T. N., Bigirimana, J., Roumen, E., Van Der Straeten, D., and Höfte, M. 2006. Eur. J. Plant Pathol. 114:381-396.

Valent, B., and Chumley, F. G. 1991. Molecular genetic analysis of the rice blast fungus, Magnaporthe grisea. Annu. Rev. Phytopathol. 29:443-467.

Van de Wouw, A. P., Cozijnsen, A. J., Hane, J. K., Brunner, P. C., McDonald, B. A., Oliver, R. P., and Howlett, B. J. 2010. Evolution of linked avirulence effectors in Leptosphaeria maculans is affected by genomic environment and exposure to resistance genes in host plants. PLoS Pathog. 6:e1001180.

Wang, J., Correll, J. C., and Jia, Y. 2015. Characterization of rice blast resistance genes in rice germplasm with monogenic and pathogenicity assays. Crop Prot. 72:132-138.

Wang, X., Jia, M. H., Ghai, P., Lee, F. N., and Jia, Y. 2015. Genome-wide association of rice blast disease resistance and yield-related components of rice. Mol. Plant-Microbe Interact. 28:1383-1392.

Wang, X., Jia, Y., Shu, Q. Y., and Wu, D. 2008. Haplotype diversity at the $P$ i-ta locus in cultivated rice and its wild relatives. Phytopathology 98:1305-1311.

Wu, W., Wang, L., Zhang, S., Li, Z., Zhang, Y., Lin, F., and Pan, Q. 2014. Stepwise arms race between AvrPik and Pik alleles in the rice blast pathosystem. Mol. Plant-Microbe Interact. 27:759-769.

Xia, J. Q., Correll, J. C., Lee, F. N., Rhoads, D. D., and Marchetti, M. A. 1993. DNA fingerprint to examine variation in the Magnaporthe grisea (Pyricularia grisea) population in two rice fields in Arkansas. Phytopathology 83:1029-1035.

Xia, J. Q., Correll, J. C., Lee, F. N., and Ross, W. J. 2000. Regional population diversity of Pyricularia grisea in Arkansas and the influence of host selection. Plant Dis. 84:877-884.

Xing, J., Jia, Y., Correll, J. C., Lee, F. N., Cartwright, R., Cao, M., and Yuan, L. 2013. Analysis of genetic and molecular identity among field isolates of the rice blast fungus with an international differential system, RepPCR, and DNA sequencing. Plant Dis. 97:491-495.

Zeigler, R. S. 1998. Recombination in Magnaporthe grisea. Annu. Rev. Phytopathol. 36:249-275.

Zhou, E., Jia, Y., Singh, P., Correll, J. C., and Lee, F. N. 2007. Instability of the Magnaporthe oryzae avirulence gene AVR-Pita alters virulence. Fungal Genet. Biol. 44:1024-1034.

\section{AUTHOR-RECOMMENDED INTERNET RESOURCE}

hierfstat software: https://github.com/jgx65/hierfstat 